\title{
An analysis of a large-scale liquid air energy storage system
}

1 Robert Morgan PhD, MBA, BEng Reader, School of Computing, Engineering and Mathematics, University of Brighton, Brighton, UK

2. Stuart Nelmes BEng Head of Engineering, Highview Power Storage, London, UK
3. Emma Gibson MSc, BEng

Director of Operations, Highview Power Storage, London, UK

4 Gareth Brett BSC

Chief Executive Officer, Highview Power Storage, London, UK
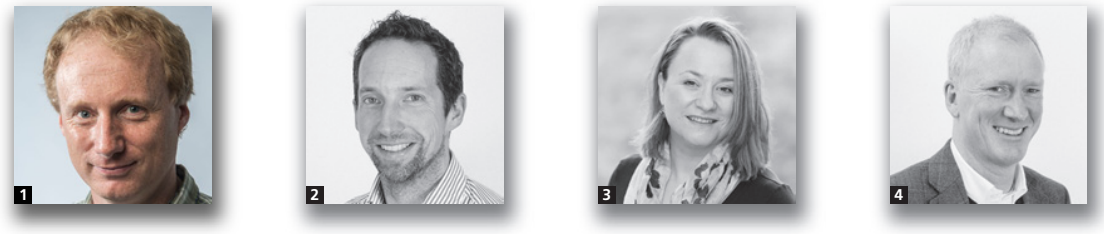

Liquid air energy storage (LAES) is a class of thermo-electric energy storage that utilises cryogenic or liquid air as the storage medium. The system is charged using an air liquefier and energy is recovered through a Rankine cycle using the stored liquid air as the working fluid. The recovery, storage and recycling of cold thermal energy released during discharge more than double the overall energy efficiency of the cycle. The demand on a storage plant in a grid support application is expected to be irregular and intermittent in response to fluctuating supply from intermittent renewable generators. This will complicate the storage of thermal energy and will mean the energy flow rates in the thermal store will vary from cycle to cycle and the state of charge of the store will also vary. This paper presents an analysis of the LAES cycle. The material and configuration of the cold thermal store is discussed in particular with reference to scale and measures to mitigate losses due to the irregular and intermittent duty cycle. The paper concludes with capital and levelised cost analysis of a reference $20 \mathrm{MW} / 80 \mathrm{MWh}$ LAES plant and a comparison of the levelised cost with other storage technologies.

$\begin{array}{ll}\text { Notation } & \\ D & \text { diameter of thermal store } \\ d & \text { effective particle diameter } \\ \mathrm{d} P / \mathrm{d} x & \text { pressure gradient along thermal store } \\ L & \text { length of thermal store } \\ T & \text { turbine } \\ u & \text { superficial velocity } \\ \varepsilon & \text { void fraction of thermal store } \\ \mu & \text { fluid viscosity }\end{array}$

\section{Introduction}

The balancing of a future power network with an increased contribution from intermittent inflexible generation will be challenging (Operating the Electricity Transmission Networks in 2020, 2011). The time shifting of excess energy production to times of high-energy demand through large-scale energy storage is one approach, potentially providing cost-effective balancing and improving the integrity of the power network (Grünewald et al., 2011). Four classes of grid-scale storage were proposed by Evans et al. (2012); mechanical, electrical, thermal and chemical of which liquid air energy storage (LAES) was identified as a class of thermal energy storage. The LAES cycle operates in three discrete stages. Electrical energy is first used to liquefy air, which is stored at low pressure in an insulated tank. When power is required, liquid is drawn from the storage tank and compressed, then heated using thermal energy from the environment. The warm highpressure gas is then expanded through a turbine to recover mechanical work that can be used to turn a generator to provide electricity back to the electricity network. The cycle energy efficiency is improved through 'cold recycle', which involves capturing and storing the cold thermal energy released during discharge and using the stored energy to reduce the work required to liquefy air during charging. Variants of the LAES cycle were first described by Smith (1977) and more recently by Ameel et al. (2013) and Morgan et al. The LAES cycle is particularly interesting to the power utilities, as the component parts are commonly found in power stations and 
industrial air separation plant. As such, the components are mature, have well-understood maintenance requirements and are available at the scales compatible with plant sizes from $10 \mathrm{~s}$ to $100 \mathrm{~s} \mathrm{MW}$, even if the configuration in which they are being used is novel. The main elements of the LAES plant (power recovery, storage and charging) can be independently sized and configured to a particular application requirement.

In this paper, the role of energy storage in the power network will be first discussed, to provide market context and identify key performance metrics. The LAES is then described, in particular the role of the thermal store in delivering simultaneously acceptable efficiency and low capital cost. The design and construction of the thermal store is then described in more detail and simulation results of a novel cellular storage concept are presented. The paper concludes with an analysis of the capital and levelised cost of LAES in comparison with other storage technologies.

\subsection{Role of storage in the power network}

The role of energy storage in the power network is complex, and depends on the generating mix, demand profile and local market regulations. Storage can have a valuable role in a power network with a significant quantity of high capital cost baseload plant (such as nuclear) and/or intermittent (such as from wind or solar) generation in the generating mix. Conversely, storage offers much less value to a power network with a high contribution of flexible generation, such as from gas-fired stations. Most power networks today are balanced by flexible generation assets with a limited role for storage. However, as more inflexible and intermittent generation is added to power networks to reduce the carbon intensity of the generated energy, an increased role for storage is expected. Strbac et al. (2012) showed that energy storage could deliver significant efficiency savings and consequently reduced cost in operating and balancing a power grid with a high contribution of intermittent renewable generation. Strbac found that storage increased the overall network efficiency, and in particular the utilisation of highly valuable renewable energy generated at times of low demand. This is due to the unique feature of storage, in acting both as a load and generation asset. Storage can therefore not only provide energy at times of excess demand, but can also absorb excess supply such as from overnight generation from a large wind farm. The surprising conclusion of Strbac's research was the low sensitivity of the value of storage to the energy efficiency of the storage device. The consequences of Strbac's analysis on the target cost and performance metrics for a large-scale energy storage system were discussed in the Liquid Air report produced by the Centre for Low Carbon Future (Strahan et al., 2013). A net round-trip efficiency (AC out to AC in) of $>50 \%$ was proposed at a cost target of $750-1250 £ / \mathrm{kW}$. It should be noted that round-trip efficiency is important in some cases, such as in an arbitrage application where the storage device shifts significant quantities of energy, or in frequency regulation where the storage device is continuously charging/discharging. However, Strbac's work identified a significant market for a low cost, modest efficiency storage technology in a future low carbon power network.

\section{Liquid air energy storage}

\subsection{The LAES cycle}

The LAES cycle consists of three main elements (see Figure 1): a charging system, discharge system and a storage system. During charging, ambient air is first compressed, cooled and expanded to produce liquid air. The liquid air is then stored at low pressure in an insulated storage tank. During discharge,

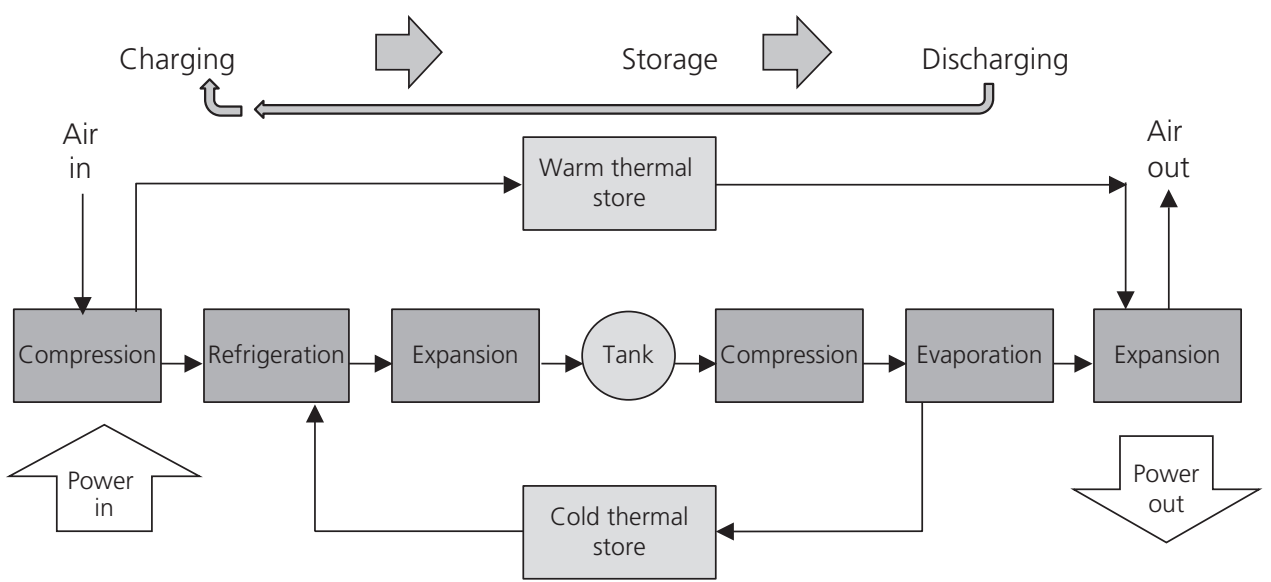

Figure 1. The LAES cycle 
liquid is drawn from the tank, compressed, heated and expanded to produce work, which can, in turn, be used to generate electricity. The cycle efficiency can be improved significantly by recovering and storing the cold thermal energy released during the heating of the cryogenic fluid during discharge and using this to pre-cool the high-pressure air prior to expansion cooling during charging. This 'cold recycle' thermally couples the charging and discharging processes by way of a (cold) thermal store. Referring to Figure 1, it can be seen that mass, as cryogenic fluid, and thermal energy flow in opposite directions to each other during charge/discharge cycles. A further improvement in efficiency can be achieved by recycling the heat of compression from the feed compressors to the charging unit, referred to as warm recycle.

Several implementations of the LAES cycle have been proposed (Ameel et al., 2013; Araki et al., 2002; Smith, 1977). The concept presented here consists of a Rankine cycle for discharge and modified Claude cycle liquefier for charging, coupled by way of a thermal and liquid air storage tank. An analysis of this cycle was previously published by Morgan et al. and will be developed further in this paper.

\subsection{Key cycle trade-offs}

In optimising any power system, the trade-offs of operating and capital cost must be simultaneously considered. To facilitate optimisation of the LAES cycle, these two financial parameters can be thought of as a trade-off of round trip efficiency and plant complexity. Other factors such as reliability, maintainability and operating life are also important but, in the first instance, understanding the basic efficiency and complexity trade-off is useful in optimising the system design. The main variables and process trade-offs are listed in Table 1.

The trade-offs of the number of turbine stages and peak cycle pressure were previously presented by Morgan et al. . From this analysis, the plant layout shown in Figure 2 with four refrigeration turbine stages was proposed and will be discussed further in this paper.

\subsection{Optimised cycle analysis - integration of cold recycle}

The Aspen Tech HYSYS process simulation package (HYSYS v7.3, 2012) was used to design and optimise the LAES cycle. The modelling approach was validated against results from a $350 \mathrm{~kW}$ pilot-scale demonstration plant (Morgan et al.), which demonstrated the predictive capability of HYSYS in modelling a LAES system. The modelling assumptions are summarised in Table 2.

Ancillary losses from coolant pumps, air blast coolers and the regeneration air flow heater were accounted for in the efficiency calculations. Previous research by Morgan considered the conventional two-turbine Claude cycle, where 'cold' and 'warm' turbines are operated in parallel, cooling in turn the

Variable Trade-offs

Number of turbine stages in the discharge unit, Closer to isothermal expansion during power recovery, increasing specific work with interstage reheating

Maximum pressure in the discharge unit (and hence round-trip efficiency) against increased number of components and complexity and therefore cost

- Increased expansion ratio and hence specific work (and therefore round-trip efficiency) against peak stresses in the high-pressure components, increasing material cost

- Increased specific work (and therefore round-trip efficiency against reduced cold recycle

Number of cold turbine stages in charging unit

Cold store design
Higher contribution of adiabatic (rather than isenthalpic) cooling and hence reduced liquefier work (and therefore increased round-trip efficiency) against number of components, plant complexity and therefore cost

- Cold store material selection, trading performance (and hence cycle efficiency) against material cost

- Cold store length to diameter ratio (improved cold recovery) against back pressure and hence parasitic losses

- Single against multi-cell design, trading higher self-discharge with plant complexity

Table 1. LAES cycle trade-off parameters 


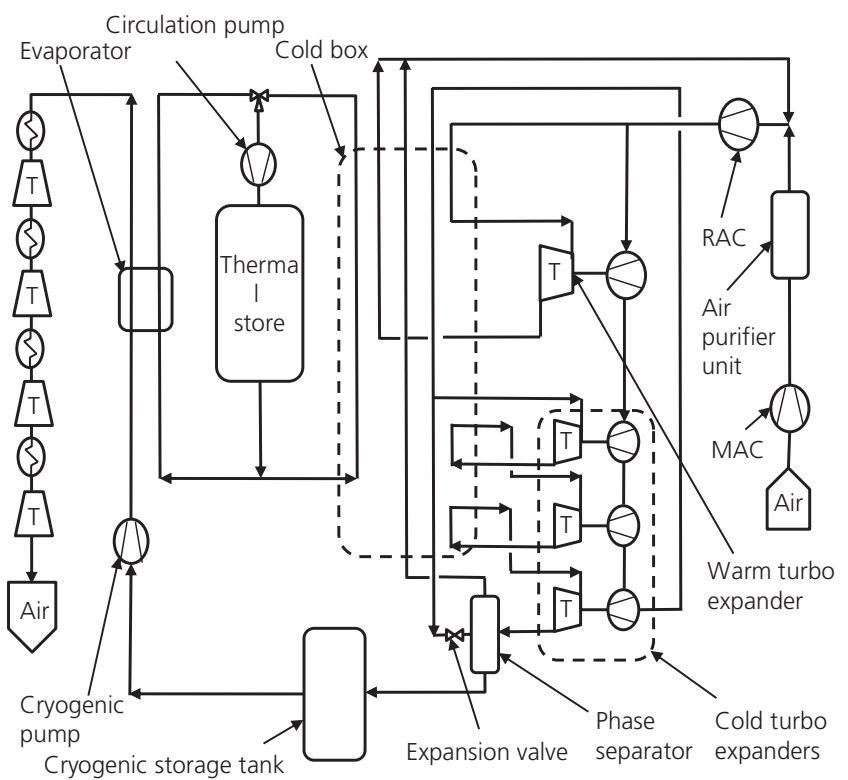

Figure 2. Optimised LAES cycle

Compressor efficiency

Turbine efficiency

Electrical machine efficiency

Cryogenic pump efficiency

Minimum approach temperature in heat exchangers

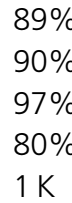

Table 2. Modelling assumptions

upper and lower parts of the cold box. This cycle has limitations in that the warm and cold stream temperatures converge in the cold box, resulting in a pinch (Figure 3) limiting the effective utilisation of the cold recycle and resulting in divergence of the warming and cooling streams in the upper parts of the cold box. The reason for the convergence is the cold recycle enters the cold box at $123 \mathrm{~K}$, whereas the cold outlet temperature before the expansion valve is $104 \mathrm{~K}$. This effectively results in a step increase in cooling capacity in the lower sections of the cold box where the cold recycle is added resulting in convergence of the heating and cooling streams at this point. To resolve this issue, the layout presented in Figure 2 is proposed. A chain of three turbines replaces the single cold turbine with interstage reheating in the cold box to target cooling to lower part of the cold box below the point of entry of the cold recycle. This means more cold recycle can be used without a pinch. The benefit of the optimised layout is shown in Figure 4 where the net round-trip efficiency of the baseline

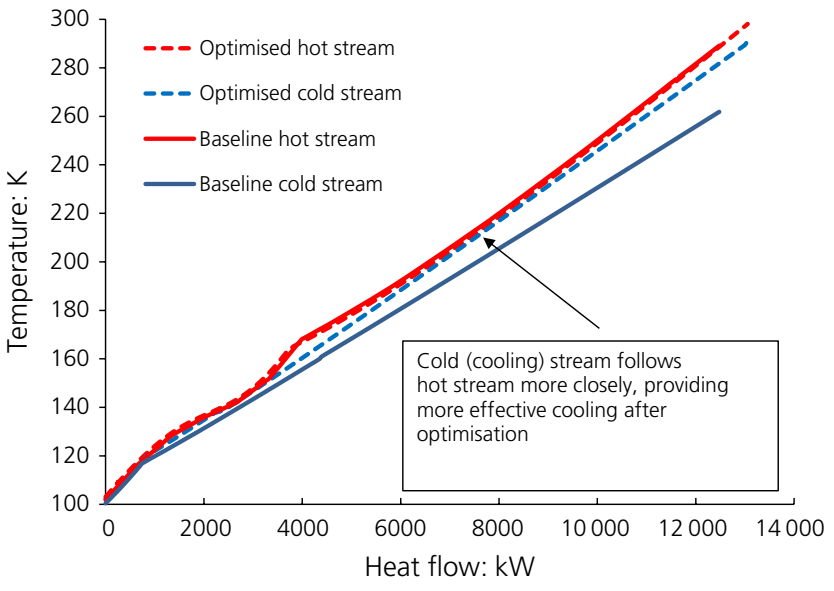

Figure 3. Temperature profiles in cold box for baseline Claude cycle and optimised cycle

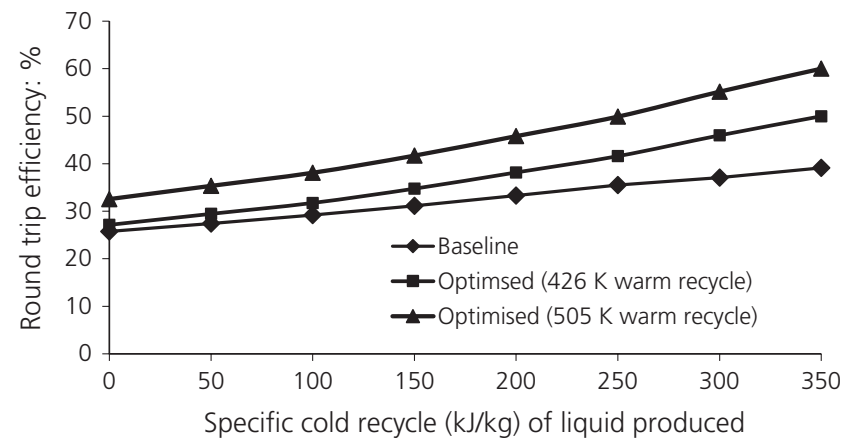

Figure 4. Comparison of round trip efficiency for baseline and optimised LAES cycles

Claude cycle (from Morgan et al.) and optimised cycles are compared for various levels of cold recycle. Two optimised cases are shown, using warm recycle recovered from the main air compressor (MAC) and recycle air compressor (RAC) to 426 and $505 \mathrm{~K}$. Key process parameters of the optimised cycle are presented in Table 3 for a $20 \mathrm{MW}$ power recovery system with a $12 \mathrm{~h}$ recharge time and $93 \%$ efficient recovery of cold recycle. For this case, a round-trip efficiency of $47 \%$ rising to $57 \%$ was calculated with the higher grade of warm recycle.

From this analysis, it can be seen that if $300 \mathrm{~kJ} / \mathrm{kg}$ (equivalent to $93 \%$ ) of the available cold can be recovered, stored and recycled with warm recycle, the target round-trip efficiency of $>50 \%$ can be achieved. 


\begin{tabular}{llll} 
Location & Temperature: $K$ & Pressure: bar & Mass flow: kg/s \\
\hline Charging (liquefier) & & & $20 \cdot 7$ \\
MAC outlet & $505 \cdot 2$ & $9 \cdot 0$ & $53 \cdot 8$ \\
RAC outlet & 526 & $56 \cdot 8$ & $34 \cdot 1$ \\
First cold turbine inlet & $164 \cdot 3$ & $56 \cdot 4$ & $34 \cdot 1$ \\
Third cold turbine outlet & $102 \cdot 1$ & $9 \cdot 0$ & $19 \cdot 7$ \\
Expansion valve inlet & $103 \cdot 1$ & $56 \cdot 2$ & $31 \cdot 8$ \\
$\quad$ Cold store outlet (charging) & $120 \cdot 1$ & $9 \cdot 0$ & $95 \cdot 5$ \\
Discharge (power recovery) & & & 60 \\
Cold store outlet (discharging) & 299 & $8 \cdot 5$ & $9 \cdot 0$
\end{tabular}

Table 3. Key process parameters for optimised LAES cycle for a $20 \mathrm{MW} / 80 \mathrm{MWh}$ plant with $12 \mathrm{~h}$ recharge time

\section{Cold store design}

The analysis presented in Section 2 demonstrates the importance of effective capture, storage and recycle of cold thermal energy on the LAES cycle efficiency. In this section, the design of the cold store will be analysed in more detail. Previous researchers have proposed a packed bed regenerator for cold thermal storage on a large scale (White, 2011). A store of this type was assumed, having the potential for high thermal efficiency, low cost and scalable to the expected size required for a utility scale LAES.

\subsection{Selection of storage media}

For the optimised cycle presented in Section 2, the thermal energy storage requirements are of the order of two thirds of the equivalent electrical energy stored in the combined liquid air and thermal stores. To investigate the practical requirements of the thermal store, a typical utility-scale $288 \mathrm{GJ}$ ( $80 \mathrm{MWh}$ ) electrical energy LAES device was considered, representing a thermal storage requirement of 181 GJ. For this analysis, it was assumed that all the thermal energy released during power recovery was stored. A packing density of 0.38 was assumed for the solid phase material, representative of loose-packed spherical particles. The key material properties, equivalent thermal store mass and relative bulk material costs for a number of common materials are presented in Table 4 .

From Table 4, it is apparent that the thermal store is a substantial structure, of the order of a $1000 \mathrm{~m}^{3}$. Careful consideration to the material selection and design of the store is critical to balance cost and thermal performance at the required scale for a grid support energy storage device. Considering the choice of solid phase material, the material must be compatible with cryogenic temperatures and tolerant to thermal cycling, which would exclude materials such as ferritic steels and many ceramics such as building bricks which would shatter due to thermal fatigue. Cost is also important considering the large quantity of material required and the capital cost sensitivity of bulk energy storage. This precludes high-performance exotic

\begin{tabular}{lccccccrr}
\hline & $\begin{array}{c}\text { Specific heat } \\
\text { capacity: } \\
\mathrm{kJ} /(\mathrm{kg} \mathrm{K})\end{array}$ & $\begin{array}{c}\text { Bulk } \\
\text { density: } \\
\mathrm{kg} / \mathrm{m}^{3}\end{array}$ & $\begin{array}{c}\text { Relative } \\
\text { unit cost }\end{array}$ & $\begin{array}{c}\text { Conductivity: } \\
\text { W/m K }\end{array}$ & $\begin{array}{r}\text { Mass of } \\
\text { store: } \mathrm{t}\end{array}$ & $\begin{array}{r}\text { Volume of } \\
\text { store: } \mathrm{m}^{3}\end{array}$ & $\begin{array}{r}\text { Relative cost } \\
\text { of store }\end{array}$ & $\begin{array}{r}\text { Max. particle } \\
\text { diameter: } \mathrm{mm}\end{array}$ \\
\hline Stainless steel & 0.46 & 7810 & 13 & 16 & 2459 & 829 & $20 \cdot 1$ & 160 \\
Copper & 0.38 & 8950 & 43 & 386 & 2977 & 875 & $80 \cdot 4$ & 3860 \\
Aluminium & 0.867 & 2700 & $10 \cdot 8$ & 137 & 1305 & 1272 & 8.8 & 1370 \\
Glass & 0.75 & 2700 & 1.5 & 0.78 & 1508 & 1470 & 1.4 & 8 \\
Gravel (quartz) & 0.71 & 2630 & 1 & 1.83 & 1593 & 1594 & 1.0 & 18
\end{tabular}

Table 4. Material properties and equivalent thermal store parameters (costs normalised to gravel) for an $80 \mathrm{MWh}$ store 


\section{PROOFS}

materials, such as many phase change materials and most metals. Key thermo-mechanical properties are

- high density and high specific heat capacity - to increase the energy density of the store and reduce the physical size (and therefore cost) of the containment structure

- thermal conductivity - a high conductivity is desirable to minimise temperature gradients within individual solid phase particles (and associated losses), but low conductivity is desirable to reduce intra-particle conduction losses and self-discharge of a partially charged store.

Maximising density and heat capacity, or, more precisely, the product of the two is clearly desirable. The desirable thermal conductivity is a more complex trade-off, and interacts with the chosen particle size and overall dimensions of the thermal store. The Biot number is a useful non-dimensional number for understanding the relationship of conductivity and particle size with relative losses. The maximum particle diameter to achieve a Biot number of $<10$ was calculated, assuming a convective heat transfer coefficient between the solid and gas phases of $50 \mathrm{~W} /\left(\mathrm{m}^{2} \mathrm{~K}\right)$, representative of a typical packed bed regenerator system. It is generally accepted that convective heat transfer will be dominant when the Biot number is $<10$, in which case the particle can be treated as isothermal. With reference to Table 4, a practical particle size of at least $8 \mathrm{~mm}$ (glass) and $18 \mathrm{~mm}$ (quartz gravel) is possible for the lowconductivity materials identified. The authors therefore conclude that a low thermal conductivity material can be selected within the constraints of a practical size of particle with the benefit of minimising intra-particle conduction and selfdischarge.

Considering all the above-mentioned factors, metallic materials are discounted due to $(a)$ cost and $(b)$ high conductivity and hence self-discharge. Naturally occurring gravels are attractive having (a) attractive thermal properties, (b) low cost and (c) wide availability.

\subsection{Store containment design}

The containment of the thermal store has a number of functions: structural support, pressure containment and thermal isolation from the environment to minimise heat leak. The store could be configured to accept the working fluid directly from the LAES process at high pressure, or through an intermediate working fluid circulated between the LAES process and thermal store at low pressure.

Considering first direct transfer, referring to Section 2, the working fluid can operate as high as 190 bar during discharge. The thermal store must therefore contain substantial pressure. Inspection of the store dimensions in Table 3 and considering the store as thin-walled pressure vessel manufactured from steel with a maximum operating stress of $300 \mathrm{MPa}$, the wall thickness would be of the order of $330 \mathrm{~mm}$. This option is considered impractical due to the manufacturing issues associated with such a large pressure vessel (of the order of $10 \mathrm{~m}$ across) of this wall thickness. An alternative approach was proposed by Araki et al. (2002) where the high-pressure working fluid was carried in pipes embedded in the solid phase material. However, conduction losses normal to the flow direction were unacceptably high even for a modest size of thermal store and this solution was discounted.

The indirect heat transfer approach uses a secondary working fluid, such as dry air circulated between the power recovery evaporator and store during discharging and cold box and cold store during charging. This approach isolated the thermal store from the high-pressure working fluid, allowing lowpressure containment of the cold storage material. The thermal efficiency of the store will be reduced due to irreversibilities in the heat transfer processes in the additional heat exchangers. Additional losses are also incurred due to pumping losses in circulating the secondary heat transfer fluid and will be discussed in the next section. Experience on a pilot-scale store (Morgan et al.) indicated that the losses associated with indirect heat transfer can be minimised by careful design of the heat exchangers and an approach temperature of $<2 \mathrm{~K}$ can be achieved, representing a $1 \%$ loss in the available energy for cold recycle. Overall, the low-pressure containment option is the only practical solution for large-scale LAES due to the large size of the containment vessel.

\subsection{Cellular storage concept}

Minimising pressure losses through the store is important not only to minimise parasitic losses but also the resulting pressure in the store which must be safely contained. The pressure losses in a packed bed regenerator can be calculated using the Ergun equation (Ergun, 1952)

$$
\text { 1. } \frac{\mathrm{d} p}{\mathrm{~d} x}=u \frac{150 \mu(1-\varepsilon)^{2}}{d^{2} \varepsilon^{3}}+1 \cdot 75 u^{2} \frac{\rho(1-\varepsilon)}{\mathrm{d} \varepsilon^{3}}
$$

Inspection of Equation 1 shows that pressure loss is a function of the square of the local fluid velocity $u$ in the store and inversely proportional to the particle diameter $d$. For a given size of store and mass flow, $u$ will be a function of the store length $L$ and diameter $D$, favouring a short, wide store. Conversely, classical analysis of a similar thermal storage concept (Hänchen et al., 2011; White, 2011) indicates that a long aspect ratio ( $L /$ $D)$ is favourable to reduce second law heat transfer losses. There will therefore be an optimal value of $d, L$ and $D$ to minimise pressure drop, heat transfer losses and self-discharge. This practically means the store should have the longest value of $L$, and smallest value of $d$ within the desired pressure drop limit. 
Traditional packed bed regenerators operating on industrial processes, such as steel and glass processing operate from a fully charged to fully discharged state and over a regular charge/discharge cycle. This makes the optimisation of $d, L$ and $D$ straightforward. In a grid support energy storage application, this will not be the case and the LAES device will operate in response to surges in electricity demand or supply (due to overproduction from intermittent renewable generation). The impact of this on the thermal store is the thermal energy transfer rate to and from the store during various charge and discharge cycles will be different, resulting in variations of the fluid phase mass flow through the store. The store will also be in a variable state of charge which will result in 'self-discharge' due to conduction between the hot and cold regions of the store reducing the quality of the stored thermal energy.

Given the above-mentioned variations in mass flow rate through the store in a grid support energy storage application, what is required is a store where the aspect ratio can be varied to match the energy and hence mass flow through the store. To achieve this goal, a cellular concept is proposed, where individual cells can be arranged in parallel or series or isolated from the fluid phase flow. Referring to Figure 5, three storage cells can be arranged in parallel, when the energy flow is very high into the store or in series when the energy flow is low to optimise thermal energy recovery at minimal pressure drop. The cellular concept enables the $L / D$ ratio to be changed, in effect producing a variable geometry thermal store. In addition, the cells can be isolated from one another limiting self-discharge of the store if one cell is partially charged. Dependent on the turndown ratio of the store (maximum to minimum energy flow rate), more cells can be added to ensure that optimal configuration can be achieved.
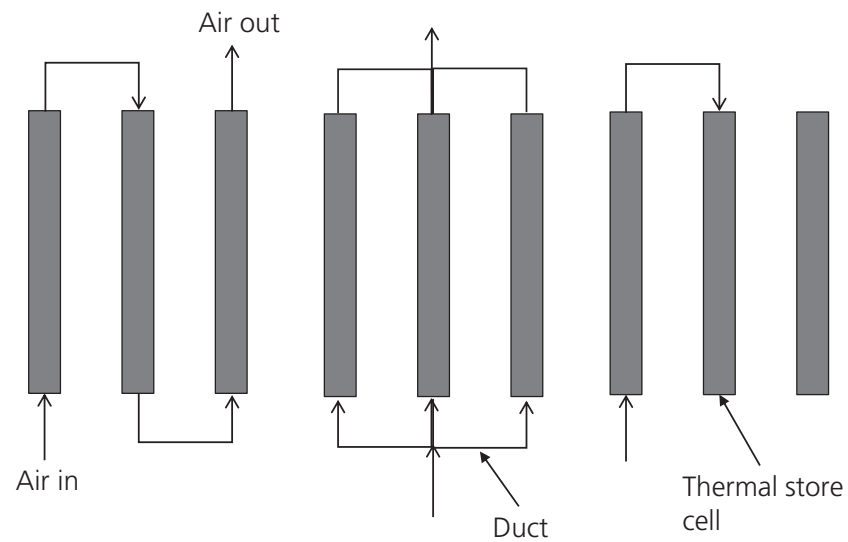

Figure 5. Multi-cell storage concept showing (a) low flow and (b) high flow paths and (c) isolated cell
A thermal store was analysed using the Flowmaster V7 (2013) software package. A series of thermal masses were connected by way of a thermal bridge (Figure 6). Conduction paths were introduced to simulate axial and radial conductions. In this case, a store of $46 \mathrm{t}$ was modelled for the previously mentioned pilot plant project. A turndown ratio of 5:1 between discharge and charge was selected to investigate the impact of variable heat transfer rates. The model was run for five repeat charge/ discharge cycles at which point the store was in cycle-to-cycle equilibrium.

The simulation was configured for three scenarios, and the steady-state thermal efficiency (energy recovered during discharge/energy available during charge) calculated, as summarised in Table 5.

From this analysis and with reference to Figure 4, the multi-cell design delivers a $4.8 \%$ improvement in efficiency compared with a single-cell storage concept for this scenario, and only $1 \%$ less than the maximum efficiency for a regenerator system optimised for thermal performance alone. Further benefits can be expected in reducing losses due to self-discharge of a partially charged storage cell, but more research on the likely duty profile of a grid-scale storage device is required to quantify these losses.

\section{Cost and value analysis}

\subsection{Reference plant: first-of-a-kind cost analysis}

Costing a liquid energy storage system is relatively straightforward as the basic component parts and sub-systems are built from established technologies such as pumps, compressors, turbines and heat exchangers. The optimal operating parameters (temperature and pressure) are also within the range of current components, minimising development requirements. This means technical solutions exist in the supply chain for all the key parts, but not necessarily at the exact specification for optimal performance and cost for a given LAES configuration. Given the forecast demand for a new storage plant, as discussed in Section 1.1, the supply chain can be expected to respond and develop suitable products.

First-of-a-kind costs for a 'reference' LAES plant were estimated through discussions with equipment suppliers. The 'sixtenths' rule (Tribe and Alpine, 1986) was used to scale costs for the nearest available component to the exact capacity required for the reference plant design. A $20 \mathrm{MW}$ capacity LAES plant with $80 \mathrm{MWh}$ of storage and a recharge time of $12 \mathrm{~h}$ was selected as a representative configuration for the expected grid support services. This represents a useful size for a utility-scale storage asset, and could be easily configured up to $100 \mathrm{MW}$ by combining five turbine trains together providing capacity and flexibility. The source cost data from the supply chain and reference plant costs are summarised in Table 5. 


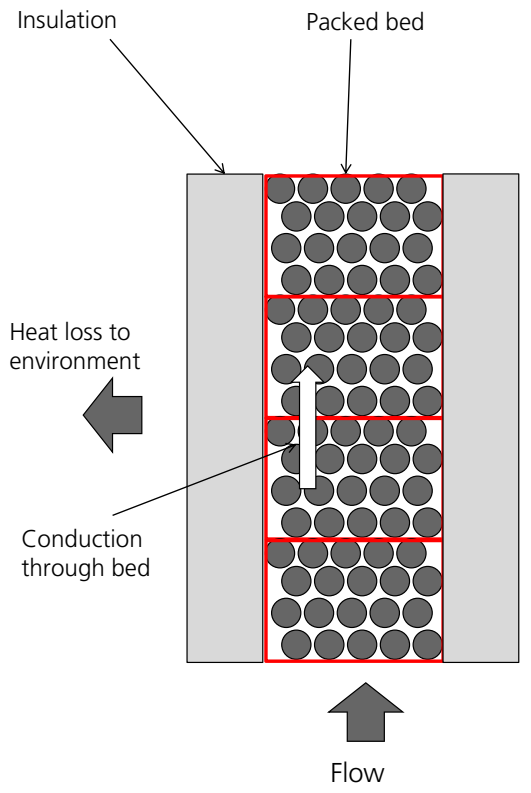

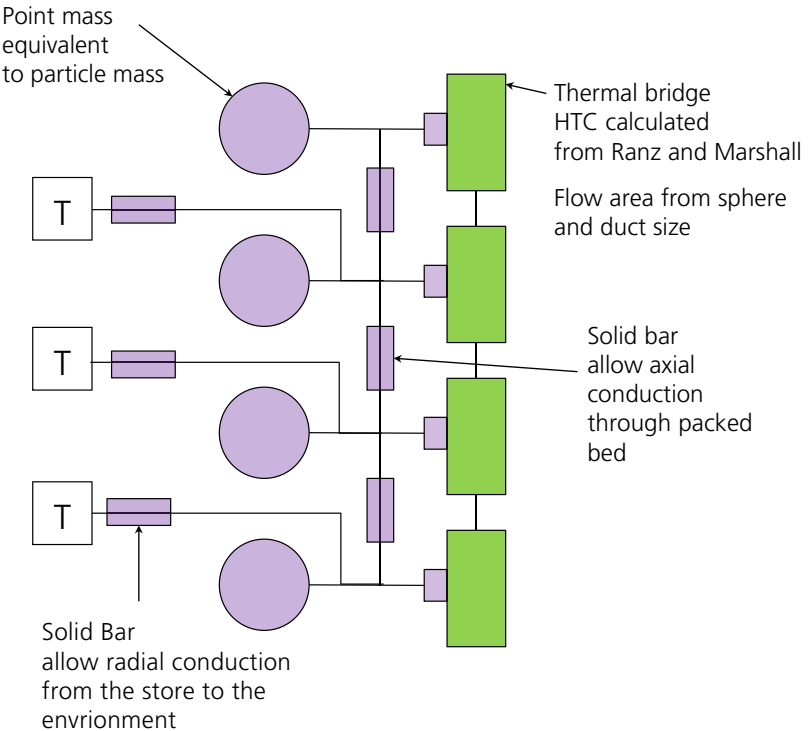

Figure 6. Schematic diagram of (a) cross-section of thermal storage cell and thermal conduction paths and (b) Flowmaster representation of thermal storage cell

No back pressure restriction, optimised for maximum

$92 \cdot 2 \%$ cold recovery

Fixed $L / D$ ratio, limited by back pressure at highest mass flow condition

Variable $L / D$ through cellular concept to maximise $L / D \quad 90 \cdot 8 \%$ ratio for a given mass flow conditions

Table 5. Comparison of thermal store efficiencies for three scenarios

From Table 6, in can be seen that the marginal cost of additional storage capacity (effectively more liquid and thermal storage tanks) is low and so additional spare inventory could be added to provide extended generation time to support the power network in the event of long but rare high demand/low supply. Such a scenario would be a high-pressure weather system over Europe during winter, where the power demand will be high and wind generation low. It is also apparent that the liquefier is the most expensive single module, representing $65 \%$ of the total cost. This means a rapid recharge capability is expensive and the provision of spare storage inventory to maintain generation availability offers a more cost-effective solution.

\subsection{Mature plant cost projection}

The component parts of the LAES plant identified during the costing of the reference plant are available as technically mature designs, but are commercially immature and therefore prices can be considered 'first-of-a-kind'. It is widely accepted that the costs of complex engineering systems reduce through repeat production through a process of 'learning'. Cost reductions derived from historic data are reported for utilityscale equipment, typically of the range of $10-25 \%$ per doubling of deployed capacity. The combined cycle gas turbine plant is considered to be the utility-scale technology most similar to the LAES plant, being made up of similar components and systems. Learning rates as high as $25 \%$ were observed during the introduction of combined cycle gas turbine technology in the 1980s (Colpier and Cornland, 2002). A more modest rate of $17 \cdot 5 \%$ was assumed to forecast the evolution of the LAES plant costs, shown in Table 5. The plant cost was assumed to be mature after the building of ten units. No cost down was applied to the storage tanks which were assumed to be already at the mature price. The forecast mature plant cost $(995 £ / \mathrm{kW})$ is within the $750-1250 \mathrm{f} / \mathrm{kW}$ range proposed as the potential value of storage, indicating the expected cost of a LAES plant is competitive with the market value of storage in a low carbon power network.

\subsection{Levelised cost analysis}

Comparing the costs of storage technologies can be challenging given the very large range of functionalities, equipment lifetimes, performance and scales involved. To overcome this problem, Sandia (Byrne et al., 2012) has developed a metric 


\section{PROOFS}

\begin{tabular}{|c|c|c|c|c|c|}
\hline & Source scale & Source cost & $\begin{array}{l}\text { Reference plant } \\
\text { scale }\end{array}$ & $\begin{array}{l}\text { First-of-a-kind cost } \\
\text { of reference design }\end{array}$ & $\begin{array}{l}\text { Mature cost of } \\
\text { reference design }\end{array}$ \\
\hline Discharge system & $3.5 \mathrm{MW}$ unit & f3.57 million & $20 \mathrm{MW}$ & f10.1 million & f5.36 million \\
\hline Charge system & $300 \mathrm{tpd}$ & f10.2 million & $2000 \mathrm{tpd}$ & f22.9 million & f12.1 million \\
\hline Storage tanks & $100 \mathrm{t}$ cryo-tank & f0.256 million & 1200 t cryo-tank & f2.46 million & f2.46 million \\
\hline Specific cost & - & - & - & 1774 f/kW & 995 f/kW \\
\hline
\end{tabular}

tpd, tonnes per day

Table 6. Reference plant cost data for a first-of-a-kind and mature plant (storage tank costs includes the thermal store)

which takes into account the various attributes and produces a single 'levelised cost of energy' over the entire duration of the analysis period. This could result in some battery systems having to be replaced several times during a 20-year study period, but does result in a comparison which is relevant for utilities, where equipment is expected to have a long life and allows for comparison with other utility equipment (e.g. fossil power plant and or transmission equipment). The results of the analysis using this methodology on LAES are shown in Figure 7. A discount rate of $7 \cdot 3 \%$ was assumed for this analysis.

From Figure 7, it is apparent that the mechanically based systems are of the lowest cost due, in large part, to their long lives. The higher cost of the battery systems is attributable, in large part, to the need to replace the systems as they degrade over time. The cost of LAES systems is very competitive with other mechanical storage devices especially given the lack of geographical constraints.

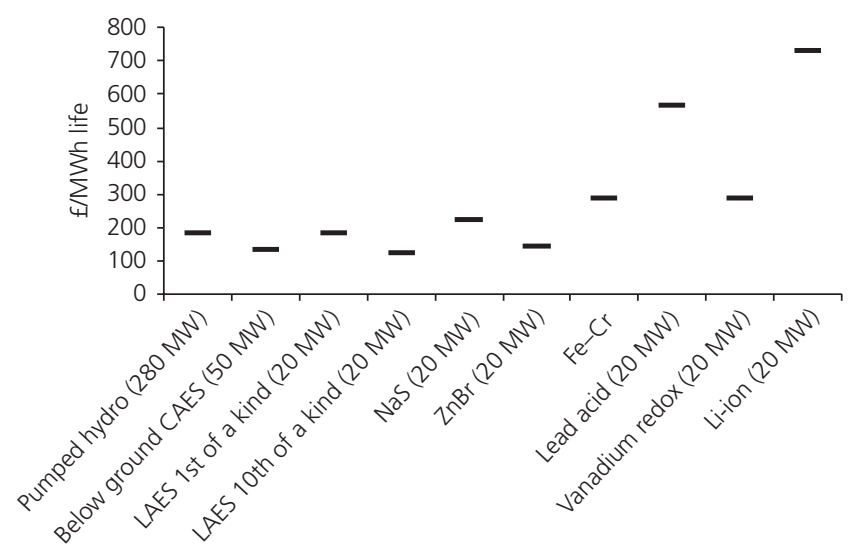

Figure 7. Levelised cost of LAES compared with other storage technologies

\section{Conclusions}

A novel LAES concept is proposed for large-scale energy storage for power grids. The capture, storage and recycle of cold thermal energy during the discharge and charging cycles is essential for achieving an efficient cycle. Careful optimisation of the liquefier, in particular the configuration of the cold turbines is essential for the effective utilisation of the cold recycle and for achieving the target round-trip efficiency of $>50 \%$. The single cold turbine normally used on an industrial liquefier is replaced by a chain of three expanders to target cooling at the lower part of the cold box where the cold recycle has no benefit.

A low-pressure cellular cold storage concept, using quartzbased gravel as the storage media, is proposed to deliver simultaneously low cost and high thermal storage efficiency and low self-discharge when partially charged.

An analysis for the first-of-a-kind and mature costs of a 'reference' LAES plant of $20 \mathrm{MW} / 800 \mathrm{MWh}$ shows that the expected commercial cost of the LAES is consistent with the expected value of storage in a low carbon power network. The levelised cost of the LAES technology is very competitive with other storage solutions mainly due to the low capital cost and long life of the technology.

\section{Acknowledgements}

The authors thank the directors of Highview Power Storage for granting permission to publish the research presented in this paper.

\section{REFERENCES}

Ameel B, T'Joen C, De Kerpel K et al. (2013) Thermodynamic analysis of energy storage with a liquid air Rankine cycle. Applied Thermal Engineering 52(1): 130-140, http://dx.doi. org/10.1016/j.applthermaleng.2012.11.037. 


\section{PROOFS}

Araki H, Nakabaru M and Chino K (2002) Simulation of heat transfer in the cool storage unit of a liquid-air energy storage system. Heat Transfer - Asian Research 31(4): 284-296, http://dx.doi.org/10.1002/htj.10035.

Byrne R et al. (2012) Methodology to Determine the Technical Performance and Value Proposition for Grid-Scale Energy Storage Systems.

Colpier UC and Cornland D (2002) The economics of the combined cycle gas turbine - an experience curve analysis. Energy Policy 30(4): 309-316, http://dx.doi.org/10.1016/ S0301-4215(01)00097-0.

Ergun S (1952) Fluid flow through packed columns. Chemical Engineering Progress 48: 88-94.

Evans A, Strezov V and Evans TJ (2012) Assessment of utility energy storage options for increased renewable energy penetration. Renewable and Sustainable Energy Reviews $\mathbf{1 6}$ (6): 4141-4147, http://dx.doi.org/10.1016/j.rser.2012.03.048.

Flowmaster V7 (2013) Mentor Graphics.

Grünewald P, Cockerill T, Contestabile M and Pearson P (2011)

The role of large scale storage in a GB low carbon energy future: issues and policy challenges. Energy Policy 39(9): 4807-4815, http://dx.doi.org/10.1016/j.enpol.2011.06. 040.

Hänchen M, Brückner S and Steinfeld A (2011) Hightemperature thermal storage using a packed bed of rocks heat transfer analysis and experimental validation. Applied Thermal Engineering 31(10): 1798-1806, http://dx.doi.org/ 10.1016/j.applthermaleng.2010.10.034.

HYSYS v7.3 (2012) Aspen Tech.
Morgan R, Nelmes S, Gibson E and Brett G, Liquid air energy storage - analysis and first results from a pilot scale demonstration plant. Applied Energy (0).

Operating the Electricity Transmission Networks in 2020 (2011) National Grid. http://www.nationalgrid.com/NR/rdonlyres/ DF928C19-9210-4629-AB78-BBAA7AD8B89D/47178/ Operatingin2020_finalversion0806_final.pdf (accessed 20/ 02/2014).

Smith EM (1977) Storage of electrical energy using supercritical liquid air. Proceedings of the Institution of Mechanical Engineers 289-298, http://dx.doi.org/10.1243/PIME_ PROC_1977_191_035_02.

Strahan D, Akhurst M, Atkins A et al. (2013) Liquid Air in the Energy and Transport Systems. Opportunities for Industry and Innovation in the UK, 021. Center for Low Carbon Futures.

Strbac G, Aundedi M, Pudjianto D et al. (2012) Strategic assessment of the role and value of energy storage systems in the UK low carbon energy future. Report for the Carbon Trust, Imperial College, London, UK. http://www. carbontrust.com/media/129310/energy-storage-systems-rolevalue-strategic-assessment.pdf (accessed 20/02/2014).

Tribe MA and Alpine RLW (1986) Scale economies and the '0.6 rule'. Engineering Costs and Production Economics 10(1): 271-278, http://dx.doi.org/10.1016/0167-188X(86)90053-4.

White AJ (2011) Loss analysis of thermal reservoirs for electrical energy storage schemes. Applied Energy 88(11): 4150-4159, http://dx.doi.org/10.1016/j.apenergy.2011.04. 030.

\section{WHAT DO YOU THINK?}

To discuss this paper, please email up to 500 words to the editor at journals@ice.org.uk. Your contribution will be forwarded to the author(s) for a reply and, if considered appropriate by the editorial panel, will be published as discussion in a future issue of the journal.

Proceedings journals rely entirely on contributions sent in by civil engineering professionals, academics and students. Papers should be 2000-5000 words long (briefing papers should be 1000-2000 words long), with adequate illustrations and references. You can submit your paper online via www.icevirtuallibrary.com/content/journals, where you will also find detailed author guidelines. 